\title{
USO ATUAL DO SOLO DO PROJETO ECOMUSEU DO CERRADO ${ }^{1}$
}

\author{
Ricardo Campos da Nóbrega² e José Imaña Encinas²
}

\begin{abstract}
RESUMO - A área do Projeto Ecomuseu do Cerrado cobre uma superfície de 8.066 km², localizados no Estado de Goiás, próximo à cidade de Brasília. Sete municípios integram a área do ecomuseu. Através da interpretação de duas imagens do satélite Landsat5, foi classificado o uso atual do solo da área do ecomuseu em matas (19\%), cerrado (23\%) e porção antropizada (58\%). Sobrepondo diversos mapas existentes da região, foi possível identificar as regiões prioritárias por município, para a correspondente conservação da diversidade biológica. O total dessas áreas prioritárias cobre uma superfície de $4.444 \mathrm{~km}^{2}$, correspondendo a 55\% da superfície do ecomuseu.
\end{abstract}

Palavras-chave: Planejamento biorregional, sensoriamento remoto e unidades de conservação.

\section{LAND-USE AT THE SAVANNA ECOMUSEUM PROJECT}

\begin{abstract}
The area of the Savanna Ecomuseum Project covers $8.066 \mathrm{~km}^{2}$, in the State of Goiás, close to the city of Brasilia. Seven counties constitute its total area. Through the interpretation of two Landsat5 TM data, the ecomuseum area has been classified as forests (19\%), savanna (23\%), and anthropic area (58\%). By overlaying several maps of the region, it was possible to identify priority areas per county, for conservation of biological diversity. The total area of these priority sites covers a surface of $4.444 \mathrm{~km}^{2}$, corresponding to $55 \%$ of the ecomuseum total area.
\end{abstract}

Keywords: Bioregional management, remote sensing and conservation units.

\section{INTRODUÇÃO}

Dos 850 milhões de hectares do território nacional, mais de 48 milhões são preservados através de unidades de conservação mantidas pelo governo federal, e em níveis estadual e municipal foram criados $237.715 \mathrm{~km}^{2}$ sob regime de proteção integral (SANTOS e CÂMARA, 2002). As unidades de conservação visam manter os recursos naturais em seu estado original, para usufruto das gerações atuais e futuras. Pode-se definir que as unidades de conservação são áreas criadas com os objetivos de harmonizar e proteger os recursos naturais, conciliando-os com as atividades humanas, além de melhorar a qualidade de vida da população local.

Em 1999, a Décima Assembléia Geral da UICN, reunida em Nova Delhi (WWF, 1999), adotou a seguinte definição para a conservação: “é a ordenação dos recursos naturais, do ar, do solo e dos minerais, das diferentes espécies de plantas e animais, inclusive do ser humano, a fim de atingir a máxima qualidade de vida da humanidade”. Atualmente, o conceito da conservação está voltado para o manejo racional sustentável dos recursos naturais, a manutenção da biodiversidade e a distribuição eqüitativa dos seus benefícios.

Os princípios internacionais explicitados na Agenda 21 , fundamentados no conceito de desenvolvimento sustentável, pressupõem uma abordagem global da problemática do meio ambiente (MMA, 1997). Uma estratégia coerente nesse conceito deverá orientarse por uma visão integrada do meio ambiente, incluindo as especificidades dos ecossistemas.

\footnotetext{
${ }^{1}$ Recebido em $1^{\circ}$.09.2003 e aceito para publicação em 10.11.2005.

${ }^{2}$ Departamento de Engenharia Florestal da Universidade Federal de Brasília. Cx. P. 04357, 70919-970 Brasília-DF.
} 
Na classificação oficial dos ecossistemas brasileiros, a área nuclear do bioma Cerrado distribui-se principalmente pelo Planalto Central brasileiro, nos Estados de Goiás, Tocantins, Mato Grosso do Sul, parte de Minas Gerais, Bahia e Distrito Federal, abrangendo 196.776.853 ha (ARRUDA, 2001). O processo de transformação do uso do solo, principalmente na região do bioma Cerrado, tem produzido, nas últimas décadas, um fenômeno de perda irrevogável de algumas características do meio ambiente natural. As pressões exercidas pelo aumento da população e a demanda de alimentos e de produtos como energia, água e outros fizeram com que os ambientes naturais sofressem drásticas transformações, num período de tempo relativamente curto.

A partir de 1960, quando ocorreu a interiorização da capital do país para Brasília e do decorrente processo de expansão das malhas viária e urbana, o cerrado passa a sofrer fortes alterações produzidas por ações antrópicas. As taxas de alteração foram significativas e se acentuaram durante as décadas de 1970 e 80, quando grandes áreas foram transformadas em pastagem e pecuária extensivas. Nessas décadas, o Brasil teve sua fronteira agrícola rapidamente deslocada em direção ao centro-norte, resultando no fato de $67 \%$ da área do Cerrado ter ficado completamente modificada (ARRUDA, 1999).

Até o final dos anos de 1980, a criação de áreas protegidas foi a estratégia central para a conservação da biodiversidade. Todavia, seus principais planejadores perceberam que somente amostras parciais e de difícil implementação não garantiriam a variedade e viabilidade genética das espécies. Constatou-se, então, que a estratégia de conservar amostras da biodiversidade através de áreas protegidas acabava por restringir ou estabelecer limites à conservação. Dessa forma, deuse origem ao desenvolvimento da idéia de expandir a escala da conservação para além dos limites dessas unidades, englobando grandes áreas e, se possível, ecossistemas inteiros (ARRUDA, 1999). Nesse contexto, passou-se a trabalhar com corredores ecológicos, que fundamentaram os alicerces dos projetos de ecomuseus.

\subsection{Projeto Ecomuseu do Cerrado}

A concepção de ecomuseu segue o princípio de se conhecer, conviver e preservar o meio ambiente, em seus aspectos naturais e humanos. Propõe-se explicar, através da ecologia, da etnografia e da vida tradicional das populações, as potencialidades da região em questão, de modo a favorecer uma fecunda reanimação cultural, visando ao desenvolvimento que crie riqueza e estabeleça também as diferenças das identidades local, regional e nacional. Assume fundamental importância para o ser humano local, uma vez que procura conservar a identidade expressa na forma de tradições e hábitos pertinentes, proporcionando o desenvolvimento sociocultural da região. Por ser uma nova concepção museográfica, permite ao visitante uma interação cultural e ambiental, fornecendo uma melhor compreensão e informação sobre o passado e o presente da região, ensejando reflexões sobre as possibilidades futuras.

A proposta de criação do Ecomuseu do Cerrado nasceu em Brasília em 1989, a partir da Coordenação de Museus da Secretaria de Cultura do governo do Distrito Federal. O projeto tinha o propósito de preservar a região das bacias dos córregos Taguatinga e Samambaia, uma área onde as características originais do ecossistema ainda eram marcantes e onde se encontrava vegetação natural abundante e diversificada, além de uma fauna significativa. Essa proposta, porém, não foi implementada. Em 1997 ressurge, através do Instituto Huah, uma organização não-governamental, a possibilidade de se proceder à sua implementação. Nessa oportunidade são redefinidos seu significado e sua finalidade, não se tratando de um simples museu ao ar livre, seguindo os princípios dos museus tradicionais, e sim de um museu descentralizado e dinâmico, alicerçado na história social e nos anseios dos seus habitantes.

A área geográfica do Ecomuseu do Cerrado abrange uma superfície de $8.066 \mathrm{~km}^{2}$, localizada entre os paralelos $15^{\circ} 21^{\prime}$ e $16^{\circ} 21^{\prime}$ ao sul do Equador e meridianos $48^{\circ}$ 04' e $49^{\circ} 14^{\prime}$ 'W Gr. No leste, é limítrofe com o Distrito Federal, que perfaz uma área de $5.814 \mathrm{~km}^{2}$. Por se encontrar próximo à cidade de Brasília, a área possui densa rede viária, embora nem todas sejam asfaltadas. Sobressaem as rodovias federais BR-060, que liga Brasília a Goiânia, e a BR-070, que vai de Taguatinga a Cocalzinho de Goiás, dando acesso às cidades de Corumbá de Goiás e Pirenópolis.

O clima da área do ecomuseu está inserido no grupo Aw, da classificação de Köppen, com uma estação seca que dura de cinco a sete meses. Nos meses chuvosos, a precipitação oscila de 1.400 a $1.500 \mathrm{~mm}$ (SEPLAN GO, 1995). De acordo com Ferri (1980), mesmo na estação seca esses solos contêm bastante água, constatação que pode justificar a folhagem verde que muitas espécies 
nativas ostentam no período seco. No entanto, a vegetação típica da região caracteriza-se por árvores e arbustos tortuosos, com aspecto xeromórfico, típicos da vegetação dos cerrados. A vegetação natural do cerrado na área de estudo apresenta as fitofisionomias de cerradão, cerrado stricto sensu, campo sujo, campo limpo, matas ciliares e matas mesofíticas.

No presente trabalho, analisou-se a situação atual do uso do solo da área do Projeto Ecomuseu do Cerrado, localizada na Região Centro-Oeste, no Estado de Goiás, através de ferramentas do geoprocessamento, visando apresentar subsídios para uma possível gestão biorregional.

\section{MATERIAL E MÉTODOS}

Visto a ampla capacidade de integração de dados e análises permitidas por sistemas de informações georreferenciadas, procedeu-se à elaboração de um banco de dados abrangendo a legislação ambiental, aspectos físicos, biológicos e conservacionistas, pertinentes à área do Ecomuseu do Cerrado. O modelo computacional adotado consistiu de um sistema de informações geográficas em ambiente Arcview 3.1, onde ficou armazenado e estruturado o correspondente banco de dados. Para tratamento, interpretação e análise de imagens, utilizou-se o software Envi 3.5.

O levantamento cartográfico definiu a escala de 1:250.000, por ser a maior escala de mapeamento disponível atualmente para a região. As cartas utilizadas foram a MIR 393, SD-22-Z-D e MIR 409, SE-22-X-B, elaboradas pela Divisão de Cartografia do Exército Brasileiro.

As duas cartas topográficas foram inicialmente digitalizadas. A etapa seguinte correspondeu ao georreferenciamento das cartas em meio digital. Dessas cartas digitais foram extraídas, em tela de computador, as informações relativas a hidrografia, altimetria, rede rodoviária e malha urbana. Além dessas cartas, também foram utilizados os seguintes materiais, que foram digitalizados: Mapa de Vegetação do Brasil na escala 1:5.000.000, produzido pelo IBGE em 1993; Mapa de Solos do Brasil na escala 1:2.500.000, produzido pela EMBRAPA em 2000; Mapa Geológico, produzido pela US Geological Survey em 1999; Mapa de limites estaduais, municipais e sedes municipais, elaborado pelo IBGE em 1999; Mapa das Unidades de Conservação, produzido pelo IBAMA em 2003; e Mapa das Áreas Prioritárias para conservação da biodiversidade no bioma Cerrado, elaborado pelo MMA em 1999.
Em função da localização da área de estudo, foram escolhidas e selecionadas as órbitas pontos 221_071 e 222_071 do satélite Landsat TM5, obtidas, respectivamente, em setembro e novembro de 1998.

A correção geométrica consistiu na identificação de todas as coordenadas x e y (longitude e latitude, respectivamente), que representavam o mesmo local nas cartas topográficas e nas imagens. Foram coletados 76 pontos em uma e 83 em outra, distribuídos uniformemente nas imagens e nas cartas topográficas. Vinte e três desses pontos ficaram localizados na zona de superposição das imagens, garantindo, assim, melhor resultado na estruturação do mosaico. O método utilizado para a correção geométrica foi o da interpolação do vizinho mais próximo, conforme descrição sugerida por Menezes (1995). Esse método determinou o valor do pixel da imagem de entrada a ser georreferenciada. Assim, seu centro ficou o mais próximo do ponto localizado na imagem de saída, permitindo a sua transferência para a correspondente grade de localização. O pixel de saída foi posteriormente remanejado, sendo mantido o seu brilho original, gerando uma imagem geometricamente corrigida. O datum horizontal assumido no georreferenciamento foi o South America 69, constante da base cartográfica das folhas utilizadas. O erro médio acumulado foi de $11,30 \mathrm{~m}$ para uma e 12,14 para a outra imagem.

A etapa seguinte consistiu da análise do realce das imagens, que visou melhorar e realçar as características visuais para posterior interpretação. O método aplicado foi de realce por ampliação linear de contraste, conforme descrição de Menezes (1995). Concluída essa etapa, produziu-se a composição colorida RGB - 453. Posteriormente, foi feito o mosaico das imagens, utilizando-se o software Envi 3.5. Em seguida, procedeu-se à localização e recorte da área abrangente do ecomuseu, criando-se, assim, uma subcena para posterior interpretação.

Para a interpretação e classificação dos tipos de uso e cobertura do solo registrados na imagem, partiuse do conhecimento de campo associado ao mapa de vegetação do IBGE. A imagem utilizada foi composta pelas bandas 4, 5 e 3, apresentadas nos canais RGB. Após a interpretação e definição das classes de uso e cobertura do solo, passou-se à classificação supervisionada da imagem. O método classificador utilizado para a associação do pixel da imagem a determinada classe foi o de Máxima Verossimilhança.

R. Árvore, Viçosa-MG, v.30, n.1, p.117-122, 2006 
A avaliação da qualidade do resultado da classificação foi realizada através da análise de acurácia, correspondendo à porcentagem de acerto do resultando. Esta análise, no software Envi, quando comparado com o resultado da classificação com a imagem, obteve uma acurácia de 95\%.

Foram realizadas duas visitas a campo, uma durante a etapa de georreferenciamento e outra durante a classificação. Além de um automóvel utilizado para deslocamentos, foram feitas cavalgadas e caminhadas. Em campo foram empregados os seguintes equipamentos: GPS da marca Garmim, modelo e-summit; máquina fotográfica Nikon N70; e binóculos Asahi Pentax. O GPS permitiu a localização de pontos previamente marcados nas cartas topográficas e escolhidos na imagem, além de servir para identificar as coordenadas de cachoeiras e cavernas, entre outros.

Foram utilizados dados disponíveis de geologia, solos e altimetria, como prognosticadores de espécies e comunidades, além de unidades de conservação, locais de beleza cênica, áreas prioritárias para conservação e áreas definidas na legislação ambiental como de preservação permanente. O objetivo foi obter, como produto final, um mapa mostrando as áreas prioritárias para a conservação da biodiversidade no âmbito do Projeto Ecomuseu do Cerrado.

\section{RESULTADOS E DISCUSSÃO}

A área do Projeto Ecomuseu do Cerrado (Figura 1) cobre uma superfície de 8.066 km², distribuídos em sete municípios do Estado de Goiás, conforme mostrado no Quadro 1, em que o maior deles, o Município de Pirenópolis, estende-se em 27,1\% e o menor, o Município de Águas Lindas de Goiás, em 2,3\% do total do território do ecomuseu.

O crescimento populacional, que nos últimos anos vem ocorrendo nos municípios do entorno do Distrito Federal de forma desordenada, tem trazido modificações bruscas das características naturais do bioma Cerrado. Parte dos municípios do entorno da capital federal que estão inseridas na área do Projeto Ecomuseu do Cerrado vem-se constituindo simplesmente em locais de moradia, sem a estrutura mínima necessária para alojar adequadamente expressiva parcela da mão-de-obra que trabalha no Distrito Federal.

R. Árvore, Viçosa-MG, v.30, n.1, p.117-122, 2006

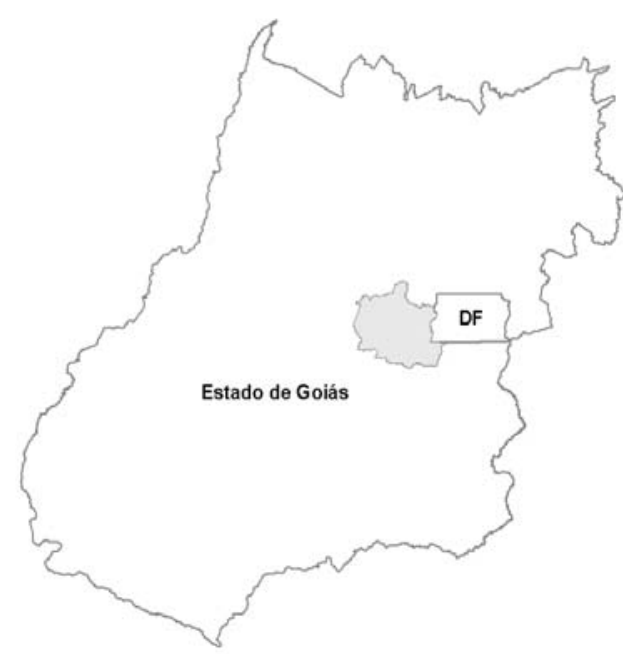

Figura 1 - Localização do ecomuseu do Cerrado. Figure 1 - Savanna ecomuseum localization.

O aumento da população e as múltiplas atividades que se desenvolveram na área de estudo exigem hoje harmonização dos processos produtivos e a preservação dos elementos naturais. Um planejamento de gestão poderá considerar aspectos da educação ambiental e da conservação in situ da biodiversidade original ainda existente. Atividades de desenvolvimento implantadas na área do ecomuseu trouxeram transformações em relação ao contexto ambiental, sendo um dos resultados dessas mudanças o atual estado da vegetação nativa, que apresenta um índice de antropização de 58\% (Quadro 1).

A vegetação natural da área do Ecomuseu do Cerrado pode ser descrita como um mosaico vegetacional, apresentando formação savânica. As matas se estendem hoje em $19 \%$ e o cerrado stricto sensu, em $23 \%$ do total da área. Uma superfície expressiva de $42 \%$ está conseqüentemente mantendo as características paisagísticas originais. Entende-se nessa classificação por matas as fitofisionamias mata de galeria, mata mesofítica e cerradão e por Cerrado, as fitofisionomias cerrado stricto sensu, campo sujo e campo limpo. A biodiversidade existente na área do ecomuseu provavelmente mantém as características típicas indicadas na literatura (BRASIL, 2002), compreendendo uma riqueza implícita numa intensa inter-relação entre elementos bióticos e abióticos. Porém, essas características e o entendimento da dinâmica entre o meio biótico e o físico na região do ecomuseu ainda são muito pouco conhecidos. 
Quadro 1 - Cobertura do uso atual do solo na área do Projeto Ecomuseu do Cerrado Table 1 -Current land-use cover at the area of the Savanna Ecomuseum Project

\begin{tabular}{|c|c|c|c|c|c|c|c|}
\hline Municípios & $\begin{array}{l}\text { Área } \\
\mathrm{km}^{2}\end{array}$ & $\begin{array}{c}\text { Matas } \\
\mathrm{km}^{2} \\
\end{array}$ & $\%$ & $\begin{array}{c}\text { Cerrado } \\
\mathrm{km}^{2}\end{array}$ & $\%$ & $\begin{array}{c}\text { Antropizada } \\
\mathrm{km}^{2} \\
\end{array}$ & $\%$ \\
\hline Abadiânia & 1.049 & 175 & 17 & 215 & 21 & 659 & 63 \\
\hline Águas Lindas de Goiás & 189 & 12 & 6 & 46 & 24 & 132 & 70 \\
\hline Alexânia & 849 & 141 & 17 & 203 & 24 & 505 & 59 \\
\hline Cocalzinho de Goiás & 1.789 & 321 & 18 & 378 & 21 & 1.090 & 61 \\
\hline Corumbá de Goiás & 1.068 & 183 & 17 & 267 & 25 & 618 & 58 \\
\hline Pirenópolis & 2.186 & 569 & 26 & 438 & 20 & 1.180 & 54 \\
\hline Sto. Antônio do Descobert & to 936 & 159 & 17 & 291 & 31 & 486 & 52 \\
\hline Totais & 8.066 & 1.559 & 19 & 1.838 & 23 & 4.669 & 58 \\
\hline
\end{tabular}

De posse dos dados digitais da imagem de satélite devidamente corrigida e interpretada, partiu-se para uma avaliação do estado de conservação da área em relação às unidades de conservação. Observou-se no Mapa de Unidades de Conservação a existência de uma unidade de proteção integral, o Parque Estadual dos Pireneus, com $26 \mathrm{~km}^{2}$ (SEPLAN GO, 1995), inserida $100 \%$ na área do ecomuseu. Na categoria de uso sustentável, encontrou-se também a APA estadual dos Pireneus, com $223 \mathrm{~km}^{2}$, abrangendo os Municípios de Cocalzinho de Goiás, Corumbá de Goiás e Pirenópolis. Existem ainda sete unidades de Reserva Particular do Patrimônio Natural.

O projeto de Conservação e Utilização Sustentável da Diversidade Biológica Brasileira (PROBIO), no âmbito do Programa Nacional da Diversidade Biológica (PRONABIO), estruturado para implementar estratégias regionais de conservação da biodiversidade dos principais ecossistemas do país, apresentou como resultado do “workshop” “Ações prioritárias para a conservação da biodiversidade do bioma Cerrado e do Pantanal” um mapa com as áreas prioritárias para conservação do bioma Cerrado (BRASIL, 1999). Fazendo o cruzamento, em SIG, de dados correspondentes dessas áreas prioritárias com os municípios do ecomuseu, foi possível identificar a área prioritária de cada município, que estaria contemplada para os estudos pertinentes (Quadro 2). Deduz-se que $4.444 \mathrm{~km}^{2}$, correspondendo a 55\% do total da área do Projeto do Ecomuseu do Cerrado, estão contemplados nas chamadas áreas prioritárias para a conservação da biodiversidade do bioma Cerrado.

Pode-se observar que todos os municípios envolvidos no projeto do ecomuseu foram, parcial ou completamente, indicados como prioritárias para a conservação da diversidade biológica. Apesar de o
Município de Águas Lindas estar na sua totalidade inserido como área prioritária, ele apresentava 70\% de sua superfície antropizada. Corrobora-se, assim, a necessidade de executar ações que permitam atingir e manter concretamente a conservação da biodiversidade da região do ecomuseu.

Quadro 2-Áreas prioritárias para conservação da biodiversidade Table 2 - Priority areas for the conservation of the biodiversity

\begin{tabular}{lccc}
\hline Município & $\begin{array}{c}\text { Área } \\
\text { Município } \\
\mathrm{km}^{2}\end{array}$ & $\begin{array}{c}\text { Área } \\
\text { Prioritária } \\
\mathrm{km}^{2}\end{array}$ & $\%$ \\
\hline Abadiânia & 1.049 & 992 & 95 \\
Águas Lindas de Goiás & 189 & 189 & 100 \\
Alexânia & 849 & 183 & 22 \\
Cocalzinho de Goiás & 1.789 & 219 & 12 \\
Corumbá de Goiás & 1.068 & 460 & 43 \\
Pirenópolis & 2.186 & 1.907 & 87 \\
Sto. Antônio do Descoberto & 936 & 494 & 53 \\
\hline Total & 8.066 & 4.444 & 55 \\
\hline
\end{tabular}

\section{CONCLUSÕES}

A integração em SIG, de imagem de satélite, GPS, dados biológicos e base cartográfica digital, permitiu classificar a área do Projeto Ecomuseu do Cerrado nas suas atuais condições de uso do solo e definir a superfície das áreas prioritárias para a conservação da biodiversidade nela existente.

Dos $8.066 \mathrm{~km}^{2}$ que compõem a superfície total do Projeto Ecomuseu do Cerrado, 19\% estão cobertos por matas, $23 \%$ por cerrado e 58\% estão antropizados.

A área prioritária para a conservação da biodiversidade do Cerrado, atendendo às recomendações do Programa Nacional da Diversidade Biológica, é de $4.444 \mathrm{~km}^{2}$, correspondendo a 55\% da superfície total do Projeto Ecomuseu do Cerrado.

R. Árvore, Viçosa-MG, v.30, n.1, p.117-122, 2006 
Os resultados alcançados poderão fornecer subsídios para a definição de políticas públicas e ações diferenciadas. Os rios e córregos com estreita faixa de vegetação seriam alvos prioritários para replantio de espécies arbóreas oriundas de viveiros comunitários. Os municípios mais antropizados, como Águas Lindas, deveriam ter atividades de educação ambiental reforçadas. Já as áreas com maior quantidade de remanescentes florestais poderiam ser alvos de criação de unidades de conservação.

\section{REFERÊNCIAS BIBLIOGRÁFICAS}

ARRUDA, M.B. Ecossistemas brasileiros. Brasília: IBAMA, 2001. 49p.

ARRUDA, M. B. Gestão integrada de ecossistemas, a escala da conservação da biodiversidade expandida. Brasília: IBAMA, 1999. 11p.

FERRI, M. G. Vegetação brasileira. São Paulo: Universidade de São Paulo, 1980. 157p.

MENEZES, P. R. Introdução ao processamento de imagens digitais de satélites e sensoriamento remoto. Brasília: Universidade de Brasília, 1995. 67p. (Série Textos Universitários).

R. Árvore, Viçosa-MG, v.30, n.1, p.117-122, 2006
BRASIL. Ministério do Meio Ambiente.

Biodiversidade brasileira. Brasília:

Secretaria de Biodiversidade e Florestas, 2002. 404p.

BRASIL. Ministério do Meio Ambiente dos Recursos Hídricos e da Amazônia Legal. A caminho da agenda 21 brasileira, princípios e ações 1992/97. Brasília: 1997. 224p.

BRASIL. Ministério do Meio Ambiente dos Recursos Hídricos e da Amazônia Legal. Ações prioritárias para a conservação da biodiversidade do Cerrado e Pantanal. Brasília: 1999. 26p.

SANTOS, T. C. C.; CÂMARA, J. B. D. (Org.) GEO BRASIL 2002, perspectivas do meio ambiente no Brasil. Brasília: IBAMA, 2002. 447p.

SEPLAN GO. Zoneamento ecológicoeconômico da área do entorno do Distrito Federal. Goiânia: Secretaria de Planejamento e Coordenação, 1995. 216p.

WORLD WILDLIFE FOUND. Áreas protegidas ou espaços ameaçados?. Brasília: 1999. 17p. (Relatório sobre o grau de implementação e vulnerabilidade das unidades de conservação federais brasileiras de uso indireto). 